\title{
Analyzing the financial soundness of public sector banks in India using CAMEL model
}

\section{B. Krishnakumare, Saurabh Singh and J. P. Pandey}

Received : 10.11.2017; Revised : 01.03.2018; Accepted : 15.03 .2018

\begin{abstract}
The Indian banking system has undergone tremendous changes in the last decade, its financial soundness and performance being paramount in the achievement of a stable and sustainable economic growth. Thus, the aim of this research was to analyze the financial soundness of the public sector banks that operate in India. In order to achieve this, one of the most popular methods for the analysis of the financial soundness of banks namely CAMEL model was used. The obtained results highlight the strength and vulnerabilities of the analyzed banks underlying the need to strengthen the concerns of the decision makers from banks to improve and increase their soundness. The study concluded that the Punjab National Bank's overall performance was very good followed by State Bank of India and the financial performance was very poor in case of IDBI.
\end{abstract}

KEY WORDS : CAMEL model, Financial soundness, Performance, Public sector banks

How to cite this paper : Krishnakumare, B., Singh, Saurabh and Pandey, J.P. (2018). Analyzing the financial soundness of public sector banks in India using CAMEL model. Internat. J. Com. \& Bus. Manage, 11(1) : 1-11, DOI: 10.15740/HAS/IJCBM/11.1/1-11. 